\title{
A method of linking functional and structural connectivity analysis in urban green infrastructure network construction
}

\author{
Yang Liu ${ }^{1} \cdot$ Ting-Ting Huang $^{1} \cdot$ Xi Zheng $^{1}$ (i)
}

Accepted: 5 January 2022 / Published online: 15 January 2022

(c) The Author(s) 2022

\begin{abstract}
Accelerated urbanization and population growth lead to the fragmentation of urban green space and loss of biodiversity. There are few studies on the integration of structural and functional connectivity to solve this problem. Our study aims to draw up a methodology to synthesize two methods of connectivity evaluation, accordingly, to construct an urban green infrastructure (UGI) network which is of great significance to maintain the stability of the urban ecosystem. Taking Beijing as a study area, we first used Morphological Spatial Pattern Analysis (MSPA) to identify the source patches, then combined with the graph theory-based landscape metrics to discuss the effect of different diffusion distances on the regional landscape connectivity and classify the importance level of the source patches. Finally, we used both least-cost path (LCP) and circuit theory to construct network and identify pinch areas in corridors for network optimization. The results show that (1) the landscape connectivity of the study area is obviously polarized. Source patches in mountain and hilly areas have good ecological bases and large areas, and the density of corridors is relatively high, which makes a large contribution to the overall landscape connectivity; Source patches in plain areas are severely fragmented, and there are only a small number of potential corridors connecting urban areas and suburban areas. (2) The UGI network is composed of 70 source patches and 148 potential corridors. The diffusion distance that is most beneficial to improve landscape connectivity is $20-25 \mathrm{~km}$. (3) 6 pinch areas that are of great significance for improving the connectivity of the landscape present the coexistence of high migration resistance and large optimization potential, and urgently need to be restored first. This study provides a method to combine the structural and the functional analysis to construct a UGI network and formulate more scientifical protection strategies for planning departments.
\end{abstract}

Keywords Urban green infrastructure (UGI) · Morphological Spatial Pattern Analysis (MSPA) · Graph theory-based landscape metrics $\cdot$ Circuit theory $\cdot$ Beijing

\section{Introduction}

Urbanization and landscape fragmentation can affect the material flow and energy balance of the urban natural ecosystems, making the system more and more vulnerable to structural changes (Alberti and Marzluff 2004) and becoming one of the main reasons for the loss of biodiversity (Breuste et al. 2015). Biodiversity plays a multi-layered role in the delivery of ecosystem services (ESs) (Mace et al. 2012), and its loss eventually leads to the decline in natural ecosystem services. Studies have shown that the

Xi Zheng

zhengxi@bjfu.edu.cn

1 School of Landscape Architecture, Beijing Forestry University, Beijing 100083, China interconnected UGI network can enhance the resilience of the city, deal with fragmentation and its subsequent negative effects and provide several ESs (e.g., species protection, biodiversity conservation and human health) (Dige 2011; Verdú-Vázquez et al. 2021). Landscape connectivity is a crucial condition for its construction (Madureira et al. 2011) and is also essential for maintaining critical ecological processes and several ecosystem services (Quatrini et al. 2019; Ferrari et al. 2019). It can be defined as structural connectivity and functional connectivity (Calabrese and Fagan 2004), both of which play an essential role in constructing the network (Battisti 2013).

Structural connectivity refers simply to landscape patterns and is not necessarily associated with the movement behavior of any particular organism (Lookingbill and Minor 2017). Previous studies have quantified connectivity 
through various metrics, such as FRAGSTATS, which has been widely used in various ecosystems with its fast and straightforward operation (Qi and Fan 2016). The most obvious limitation of this method is that too many types and quantities of index lead to the representation results of some metrics overlap to a certain extent. The rationality of metric selection directly affects the accuracy of evaluation results (Lookingbill and Minor 2017). MSPA is an image processing method that relies on land use data to quickly and objectively identify seven landscape classes that are important for maintaining connectivity (Riitters et al. 2009; Shi and Qin 2018). It has been used in different world countries for GI assessment at national (Wickham et al. 2009), regional (Carlier and Moran 2019) and urban scales (Shukla and Jain 2019). However, as with FRAGSTATS landscape metrics, MSPA is also difficult to explain the response of the ecological process to landscape pattern and quantify the relative importance of landscape elements accurately (Wang and Liu 2019). Therefore, the graph theory-based connectivity metric has been successfully applied to landscape ecology to make up for this defect (Rayfield et al. 2011). The comprehensive evaluation of integrated index of connectivity (ICC) and probability of connectivity (PC) can incorporate the diffusion distance and behavioral response of species into the analysis and estimate the strength of ecological flow between patches (Pascual-Hortal and Saura 2006).

Functional connectivity is closely related to species' habits and perception (Uezu et al. 2005; Lookingbill and Minor 2017), with high operability in ensuring the integrity and continuity of the urban ecological process (Wang and Liu 2019). The measurement is represented by the LCP model (Correa Ayram et al. 2016), which assumes that the connectivity between patches can be estimated according to the characteristics of the landscape matrix that can promote or hinder species migration. But the species dispersal behavior is premarily random, so it isn't easy to achieve this goal only by using LCP analysis (Beier et al. 2009; Cushman et al. 2013). In recent years, methods with strong species correlation and high reliability, such as systematic conservation planning (SCP) and network analysis (Cimon-Morin and Poulin 2018; Fenu and Pau 2018), can reflect the degree of coincidence between specific species' behavior and network construction to the greatest extent. But in large-scale research, due to the variety of species involved, migration behavior has great randomness. It is not appropriate to simulate the best corridors only based on specific species because these corridors may not be used by other species. Moreover, these methods usually cost a lot of workforce and expense, so they may not be optimal planning methods in large-scale research. Random walk theory is more consistent with the behavioral characteristics of species than the methods mentioned above (Song and Qin 2016). Significantly, the circuit-theoretic model is one of the most widely used connectivity approaches (McRae et al. 2016) in biodiversity conservation at broad spatial scales (Dickson et al. 2019), involving the construction of ecological security pattern (Huang et al. 2019), biodiversity conservation planning (Yin et al. 2019; Grafius et al. 2017), landscape genetics (Spear et al. 2010; McRae and Beier 2007), and other disciplines. The model has been proved to predict the way of gene flow in heterogeneous landscapes, identify ecological networks by giving different ecological meanings to physical quantities (such as resistance, current and conductivity), and combine the advantages of random walk theory and graph theory. It should be emphasized that the simulation does not respond to the diffusion of specific species but the diffusion of several species with similar diffusion ability or habitat requirements. Although the results may not be appropriate due to simulating the migration of a generalized species, the efficient algorithm can quickly process the network of millions of nodes or grid cells simultaneously. Especially for the complex urban environment, this method has irreplaceable advantages in predicting the movement mode of random walk species, estimating the probability of successful transmission or death, and measuring the connectivity of protected areas. It also has high accuracy in constructing corridors in the absence of total population size, migration rate, or other data (McRae et al. 2008).

In general, landscape connectivity abstractly expresses the ability of species to move and survive in the landscape and the degree of inhibition of landscape elements on it. It is difficult to fully reflect the material and energy flow in the region when only a single type of connectivity is considered (An et al. 2020). The landscape connectivity evaluation methods should develop to the direction of comprehensive measurement of structural connectivity and functional connectivity, further reveal the relationship between landscape structure, species migration behavior or specific ecological process and landscape connectivity, and give full play to the advantages of different methods, to more clearly guide UGI network construction. Some scholars have tried to combine MSPA and circuit theory to construct the regional ecological network for specific species (An et al. 2020) and have verified the rationality and feasibility of this comprehensive approach. But it is important to note that different diffusion distances will affect the region's overall connectivity and the probability of patch connectivity (Verbeylen et al. 2003). In Ann's research, the lack of reasonable discussion and verification of distance threshold is still a challenge.

The primary aim of this paper is to protect urban biodiversity sustainably and establish a comprehensive UGI network. Mapping the current structure landscape elements and analyzing their internal functional connection are two essential steps in the process of the UGI network construction (Capotorti et al. 2015). To achieve this, we proposed that circuit theory combined with MSPA and landscape connectivity 
metrics can help relevant urban planning departments determine the priority protection elements in UGI network and supplement the potential connecting corridors. The following issues were addressed in this paper: (1) How to quickly extract structural features of green infrastructure and identify core elements, (2) how to determine the best green space construction distance and quantify the relative importance of source patches, and (3) how to construct corridors and determine the priority conservation areas by current density for network optimization.

\section{Materials and Methods}

\section{Study Area}

Beijing is located at $115^{\circ} 25^{\prime} \mathrm{E}-117^{\circ} 30^{\prime} \mathrm{E}, 39^{\circ} 26^{\prime} \mathrm{N}-41^{\circ} 03^{\prime} \mathrm{N}$, with a total area of $16,410.54 \mathrm{~km}^{2}$ (Fig. 1). As the capital of China, its development has been attracting attention, and its planning mode is often used to be a reference sample for other cities in China. However, in the past 30 years, with the rapid development of economy, despite several urban planning revisions, more and more practical problems have been exposed in Beijing's urban development, such as the acceleration of urban population expansion, the rising of energy consumption and environmental pollution, the sharp decline of biodiversity, and the increase of urbanization rate from $55 \%$ in 1978 to $86.5 \%$ in 2017, with an increase of more than $30 \%$. The contradiction between urban sprawl and ecological protection is becoming increasingly acute, which aggravates the disharmony among urban population, natural resources, and environment. The current development situation of Beijing shows that although the planning has played a certain role in controlling and guiding the spatial layout of urban green space, it largely ignores that maintaining biodiversity is an important prerequisite for the UGI network to perform its ecological functions.

Facing the realistic goal of urban sustainable development and the common problems in the process of urbanization in China, Beijing Planning Department has clearly recognized the great significance of green space for urban development, aiming at speeding up the fine management of urban streets and idle land within the city, and promoting the sustainable development of ecological conservation areas around the city. As far as biodiversity protection is concerned, active measures have also been taken. Government plans to carry out a comprehensive biodiversity survey of four types of areas in Beijing: urban green space, plain forest, mountain forest and wetland, and establish a "Beijing biodiversity database". However, due to due to neither enough observational data nor proper planning methods, the exploration of reshaping the coordinated development pattern of Beijing's population, resources and environment still needs further exploration. Therefore, for UGI network planning, new ideas and methods must be introduced to ensure that the effective use of urban land and the management of natural ecosystems benefit the residents and biodiversity of the city and its surroundings. Comprehensively considering the structure and
Fig. 1 The spatial location and land use types of the study area

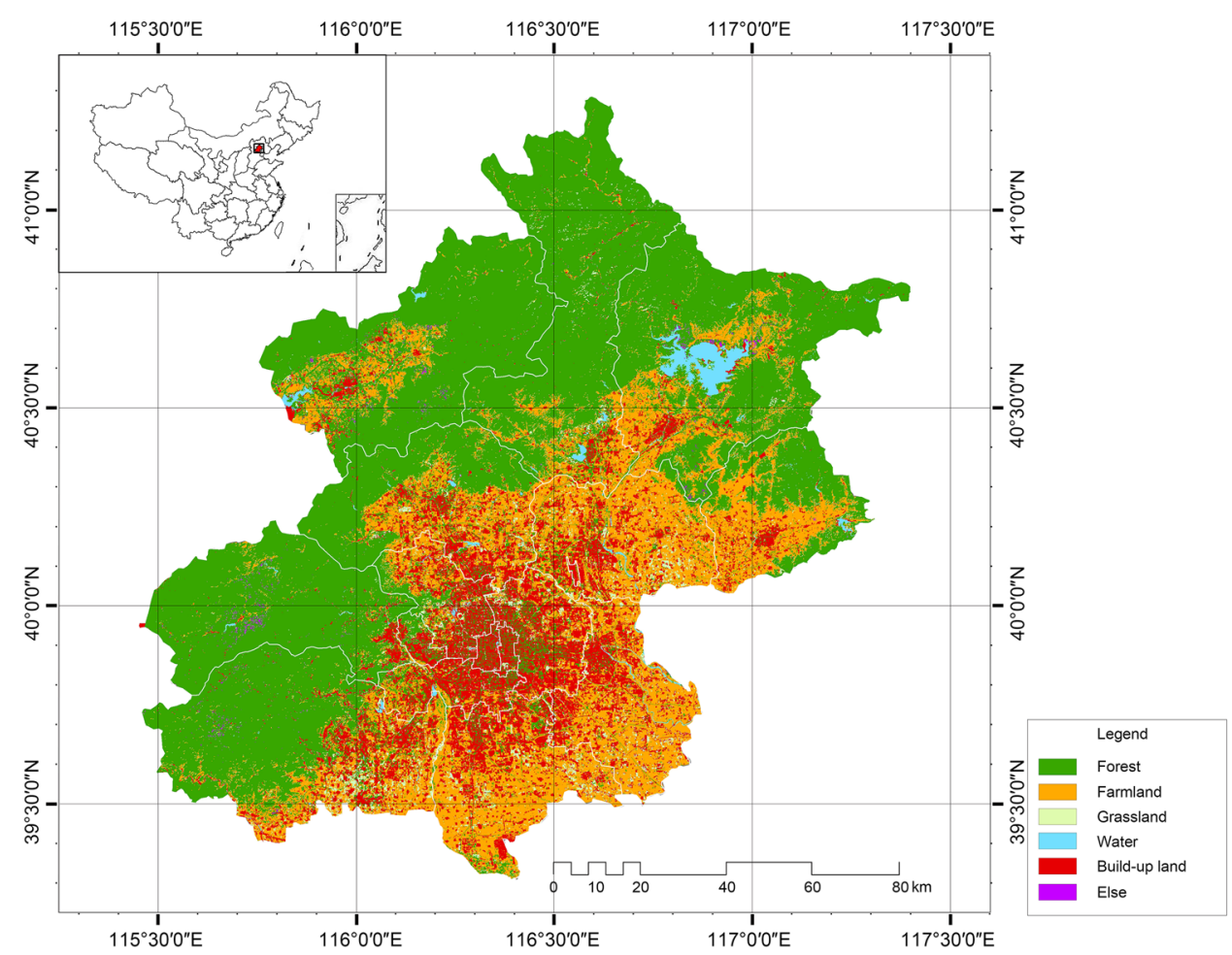


function of urban green space and constructing a systematic network is an effective way to achieve a holistic urban sustainable development model to deal with predictable urbanization problems.

\section{Methods}

\section{Data sources}

The Land-Sat 8 remote sensing satellite data and digital elevation data with a spatial resolution of $30 \mathrm{~m}$ were downloaded from Geospatial Data Cloud (http://www.gscloud. CN). Atlas of the Beijing Overall Planning (2016-2035) were downloaded from the Beijing Municipal Commission of Planning and Natural Resources (http://ghzrzyw.beijing. gov.cn/).

Firstly, based on ERDAS software platform, the topographic map of the study area is used for geometric correction of TM remote sensing data after band fusion. Then, the remote sensing images were interpreted into seven types: farmland, forest land, grassland, water area, built-up land and other land (Fig. 1) by supervised classification method, of which forest land, grassland and water area are defined as components of UGI. Finally, the land use map was converted to raster format with a cell size of $30 \mathrm{~m} \times 30 \mathrm{~m}$.

\section{Source patches extraction based on MSPA landscape structure analysis}

MSPA is a method based on a series of morphological transformations such as erosions, geodesic dilations, reconstruction by dilation, anchored skeletonization, etc. (Table S1) (Vogt et al. 2009).It can segment binary patterns into seven mutually exclusive patterns: core, islet, loop, bridge, perforation, edge, and branch (Soille and Vogt 2009; Vogt et al. 2009), among which core area and bridge area have important ecological significance for landscape connectivity.

In this study, we used MSPA to initially select the core patches from the perspective of landscape structure. Firstly, based on the land use map of Beijing, Arc GIS was used to extract the forest land, grassland, and water area as the foreground, and the remaining landscape types were set as the background to form a riff format binary map. Then, using Guidos Toolbox software for 8 neighborhood analyses, the edge width was set to 1 pixel, and the landscape type "core area" was extracted. In addition, we note that patch area also plays a decisive role in habitat heterogeneity and biological carrying capacity, and scattered small patches play a limited role in maintaining natural ecosystem services. Therefore, we screened the extracted core patches according to the cumulative proportion of patches areas of different specifications to the total area of regional green space and removed the fragmentary patches. Finally, source patches determined by MSPA and patch area were used to calculate landscape connectivity in the following steps.

The total area of the study area is large and the landscape distribution is relatively concentrated. Therefore, the scale with a grid size of $30 \mathrm{~m} \times 30 \mathrm{~m}$ can preserve the main landscape elements in the study area, and meet the requirements of research data accuracy.

\section{The distance threshold determination and importance classification of source patches on an analysis of graph theory-based landscape metrics}

In the evaluation process, the distance threshold is the critical factor affecting the connectivity evaluation results whether from a structural or functional perspective. If the distance threshold is set too low, the patches in the region are not connected, and the fragmentation is severe; If the distance threshold is set too high, the patches are interconnected and belong to the same component. Neither of the above two situations can reflect the actual landscape connectivity of the area. The graph theory-based landscape metrics introduces the distance threshold as an important parameter to estimate the existence and strength of ecological flow between patches. It integrates landscape pattern analysis and functional analysis. It is not only a vital link that combines MSPA and circuit theory in a complementary manner but also an essential node in the transition of green infrastructure network construction from structural connectivity analysis to functional connectivity analysis.

Distances between patches can be defined as Euclidean distances or, preferably, as minimum cost distances that take into account the variable movement preferences and abilities of the species through different land cover types (Verbeylen et al. 2003). The appropriate distance threshold needs to take the species migration characteristics as a reference to improve the applicability and scientificity of the planning results. Beijing's climate zone and its geographical location are the pathways through which a variety of migratory birds migrate in spring and autumn and it plays an essential role in protecting migratory birds in northern China. Therefore, the range of bird activity has a particular reference value in selecting the appropriate distance threshold. According to the relevant literature, the average search range of birds is 30-32,000 m. The dominant bird species like Anseriformes birds with a search range of about $10 \mathrm{~km}$, and most species such as Swans and Grey Cranes have been included in the Red List of Endangered Animals (Ye 2019; Liu et al. 2010).

In this study, we firstly selected source patches identified by MSPA. Then we calculated the integral index of connectivity (ICC), probability of connectivity (PC), the 
number of components (NC), and importance index (dI) of them by Conefor Sensinode 2.6 software (Saura and Pascual-Hortal 2007; Wang and Liu 2019). PC is defined as the probability that two points randomly placed within the landscape fall into habitat areas that are reachable from each other, which is negatively correlated with the distance between the two points. IIC is a metric based on a binary network, which ranges from 0 to 1 and increases with improved connectivity. It is different from the PC directly assess the probabilities for dispersal between all pairs of patches, ICC uses estimates of diffusion possibilities between all pairs of patches (Pascual-Hortal and Saura 2006). Furthermore, ten distance thresholds $(1 \mathrm{~km}$, $5 \mathrm{~km}, 10 \mathrm{~km}, 15 \mathrm{~km}, 20 \mathrm{~km}, 25 \mathrm{~km}, 30 \mathrm{~km}, 35 \mathrm{~km}, 40 \mathrm{~km}$, $45 \mathrm{~km}$ ) were set according to the search range of birds. Then the most appropriate distance threshold was obtained by calculating and analysing the change of metric value with distance. To show the changing trend of each metric more clearly, the distance threshold here was set to be larger than the maximum search range of birds. Finally, under the optimal distance threshold, the source patches were divided into four grades according to the natural breaks in importance index (dI') value. dI' was obtained by $\mathrm{dI}$ normalization.

The metrics calculated following Eqs. (1), (2), (3), and (4):

$$
\begin{gathered}
\mathrm{ICC}=\frac{\sum_{\mathrm{i}=1}^{\mathrm{n}} \sum_{\mathrm{j}=1}^{\mathrm{n}} \frac{\mathrm{a}_{\mathrm{i}} \times \mathrm{a}_{\mathrm{j}}}{1+\mathrm{l}_{\mathrm{ij}}}}{\mathrm{A}_{\mathrm{L}}^{2}} \\
\mathrm{PC}=\frac{\sum_{\mathrm{i}=1}^{\mathrm{n}} \sum_{\mathrm{j}=1}^{\mathrm{n}} \mathrm{p}_{\mathrm{ij}}^{*} \times \mathrm{a}_{\mathrm{i}} \times \mathrm{a}_{\mathrm{j}}}{\mathrm{A}_{\mathrm{L}}^{2}} \\
\mathrm{dI}=\frac{\mathrm{I}-\mathrm{I}_{\text {remove }}}{\mathrm{I}} \times 100 \%
\end{gathered}
$$

$\mathrm{dI}^{\prime}=0.5 \times \mathrm{dIIC}+0.5 \times \mathrm{dPC}$

where $n$ represents the quantity of patches; $a_{i}$ and $a_{j}$ refer to the areas of patches $i$ and $j ; l_{i j}$ represents the connection between patches $i$ and j; AL is the total area; $p^{*}{ }_{i j}$ represents the maximum possibility of species migration between patches $i$ and j; I is the connectivity index value of ICC and PC; $\mathrm{I}_{\text {remove }}$ is the connectivity index after removing patch $\mathrm{i}$ from the landscape; $\mathrm{dI}$ 'is the normalized index of dI.

\section{Corridor construction based on circuit theory}

Circuit theory considers landscapes as conductive surface and assigns different resistance values to landscape patches according to resistance factors such as vegetation coverage type and slope, low resistance has permeability and promotes gene flow and species migration. In contrast, high resistance will cause movement barriers (Fig. 2) (McRae et al. 2008). Figure $2 \mathrm{~b}$ shows three types of landscape patches: assigned unit, infinite, and zero resistance. Cells with infinite resistance are regarded as species migration obstacles and are dropped (black), cells with zero resistance are consolidated into a single node (white) and considered as ecological areas, and others with a finite resistance are converted to nodes in the circuit (gray). Adjacent nodes are connected by resistors, with resistances reflecting a function of the resistances of the cells they connect. Figure $2 \mathrm{a}$ shows that when the quantity of electric charge is constant, the heterogeneity of the landscape leads to different densities of currents in the area, representing the magnitude or frequency of the possibility of species passing through different nodes or paths (McRae et al. 2008).

In this study, for different types of land use, highly suitable forest land represents an ideal habitat for birds and most medium-sized mammals, so they were assigned a low resistance value. Although the grassland cannot be regarded as a favorable habitat, it is less disturbed by human activities, and act as a weaker barrier to movement

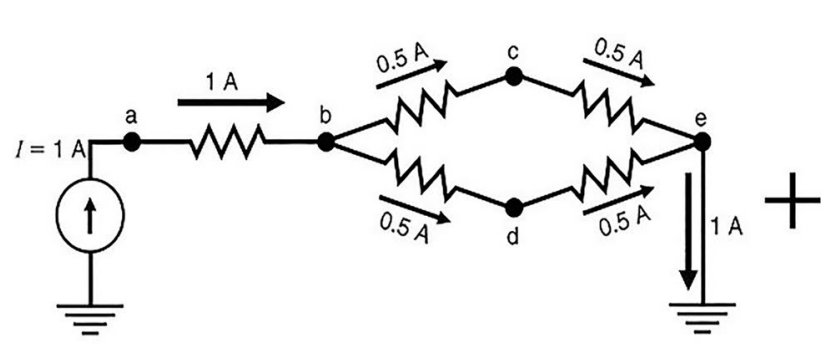

(a)
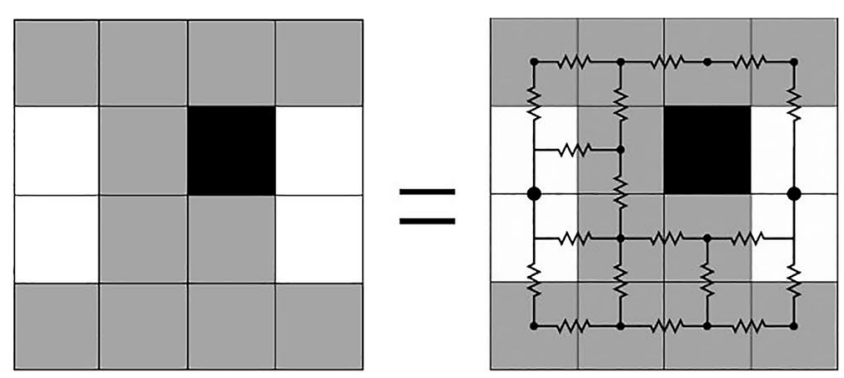

(b)

Fig. 2 Circuit theory schematic diagram. (a) Electron random walk simulates the spread of species. (b) Circuit grid applied to raster analysis. (McRae et al. 2008) 
than built-up land. Built-up land is the least suitable landuse type for animal migration which has become a physical barrier in many cases. For different landscape patterns, the structure determines their resistance value. Core and bridge areas are conducive to species habitat and diffusion, so they were assigned a low resistance value. Islet and branch areas are isolated from each other, and the possibility of internal material and energy exchange is relatively slight, so they were assigned a high resistance value. Additionally, the topography is also an essential factor affecting species migration. Low altitude and relatively flat terrain are more favorable for species diffusion. According to the impact of different landscape pattern classes identified by MSPA, land use types, elevation, and slopes on biological migration, the corresponding resistance values were assigned by referring to relevant literature (Xu et al. 2015; Shi and Qin 2018; Huang et al. 2019) (Table 1) in combination with expert opinions. Among them, the resistance values of grassland and else land are expert-assigned. The index weights were assigned by AHP software. Finally, the Linkage Mapper was used to create a cost-weighted distance

Table 1 Resistance value and weight of different resistance layers (1-100, unitless) (Xu et al. 2015; Shi and Qin 2018; Huang et al. 2019)

\begin{tabular}{|c|c|c|c|}
\hline Resistance layer & Weight & Resistance Factor & $\begin{array}{l}\text { Resistance } \\
\text { Value }(0-100)\end{array}$ \\
\hline \multirow{8}{*}{$\begin{array}{l}\text { MSPA Landscape } \\
\text { Types }\end{array}$} & \multirow[t]{8}{*}{0.36} & Core & 1 \\
\hline & & Bridge & 10 \\
\hline & & Loop & 30 \\
\hline & & Branch & 60 \\
\hline & & Islet & 15 \\
\hline & & Pore & 30 \\
\hline & & Perforation & 80 \\
\hline & & Background & 100 \\
\hline \multirow[t]{6}{*}{ Land Use Types } & \multirow[t]{6}{*}{0.25} & Forestland & 20 \\
\hline & & Grassland & 30 \\
\hline & & Cultivated land & 50 \\
\hline & & Water Area & 70 \\
\hline & & Unused Land & 60 \\
\hline & & Built-up land & 100 \\
\hline \multirow[t]{5}{*}{ Slope } & \multirow[t]{5}{*}{0.17} & $\mathrm{i} \leq 8^{\circ}$ & 1 \\
\hline & & $8^{\circ}<\mathrm{i} \leq 15^{\circ}$ & 20 \\
\hline & & $15^{\circ}<\mathrm{i} \leq 25^{\circ}$ & 60 \\
\hline & & $25^{\circ}<\mathrm{i} \leq 35^{\circ}$ & 80 \\
\hline & & $\mathrm{i}>35^{\circ}$ & 100 \\
\hline \multirow[t]{5}{*}{ Elevation } & \multirow[t]{5}{*}{0.22} & $\mathrm{~h} \leq 100 \mathrm{~m}$ & 1 \\
\hline & & $100 \mathrm{~m}<\mathrm{h} \leq 300 \mathrm{~m}$ & 20 \\
\hline & & $300 \mathrm{~m}<\mathrm{h} \leq 600 \mathrm{~m}$ & 60 \\
\hline & & $600 \mathrm{~m}<\mathrm{h} \leq 1000 \mathrm{~m}$ & 80 \\
\hline & & $\mathrm{h}>1000 \mathrm{~m}$ & 100 \\
\hline
\end{tabular}

surface and simulate the potential corridors between source patches.

In addition, it should be noted that the irregular or sharp edges of patches caused by landscape fragmentation will affect the biotic or abiotic processes that operate at the interface between two ecosystem types, that is, edge influence (EI) (Banks-Leite et al. 2010). Existing research results show that when the width of the corridor exceeds $400 \mathrm{~m}$, the edge effect can be alleviated to a certain extent, and the corridor narrower than $1200 \mathrm{~m}$ will not have a real internal habitat (van Schalkwyk et al. 2020; Carlson et al. 1989; Bueno et al. 1995). Harris and Sheck suggested that to meet the migration of more species, the appropriate corridor width should be measured in kilometers (Harris and Sheck 1991). Therefore, we set the corridor width to $1.2 \mathrm{~km}$ and counted the area and proportion of the land use types that make up the corridor.

\section{Optimization of the UGI network}

Judging the importance of landscape elements to the overall connectivity and identifying the pinch areas in corridors to improve the landscape connectivity is the key to UGI network optimization (Kavanagh et al. 2004). We used the Centrality Mapper tool to evaluate the importance of source patches by calculating the current flow centrality (Carroll et al. 2012). The more significant current flow centrality, the more critical the patch is to maintain the overall connectivity of the entire network. The Pinch-point Mapper tool can calculate the current density through source patches and corridors to determine the pinch areas (McRae et al. 2008). "All to one model" was selected, and the corridor width was set to $1.2 \mathrm{~km}$. This calculation mode obtains the accumulated current value of the grid unit through iterative operation, that is, one source patch in the landscape is grounded, and the other patches are input with 1 Amp current to calculate the current value from all patches. The area with high current density in connecting corridors is the pinch area, where species are likely to move through, or there is no alternative path. The significance of the pinch point is that if it is removed or changed, it will have a more significant impact on functional connectivity.

In summary, we first used MSPA to select source patches that are important for maintaining structural connectivity. Then the graph theory-based landscape metrics were used to explore the suitable distance between source patches and quantify the importance of the patches. After that, considering the diversity of species and the consumption of workforce and materials, we chose a circuit model to build corridors. Furthermore, the pinch areas which have an important influence on species migration were identified, and corresponding optimization strategies were 


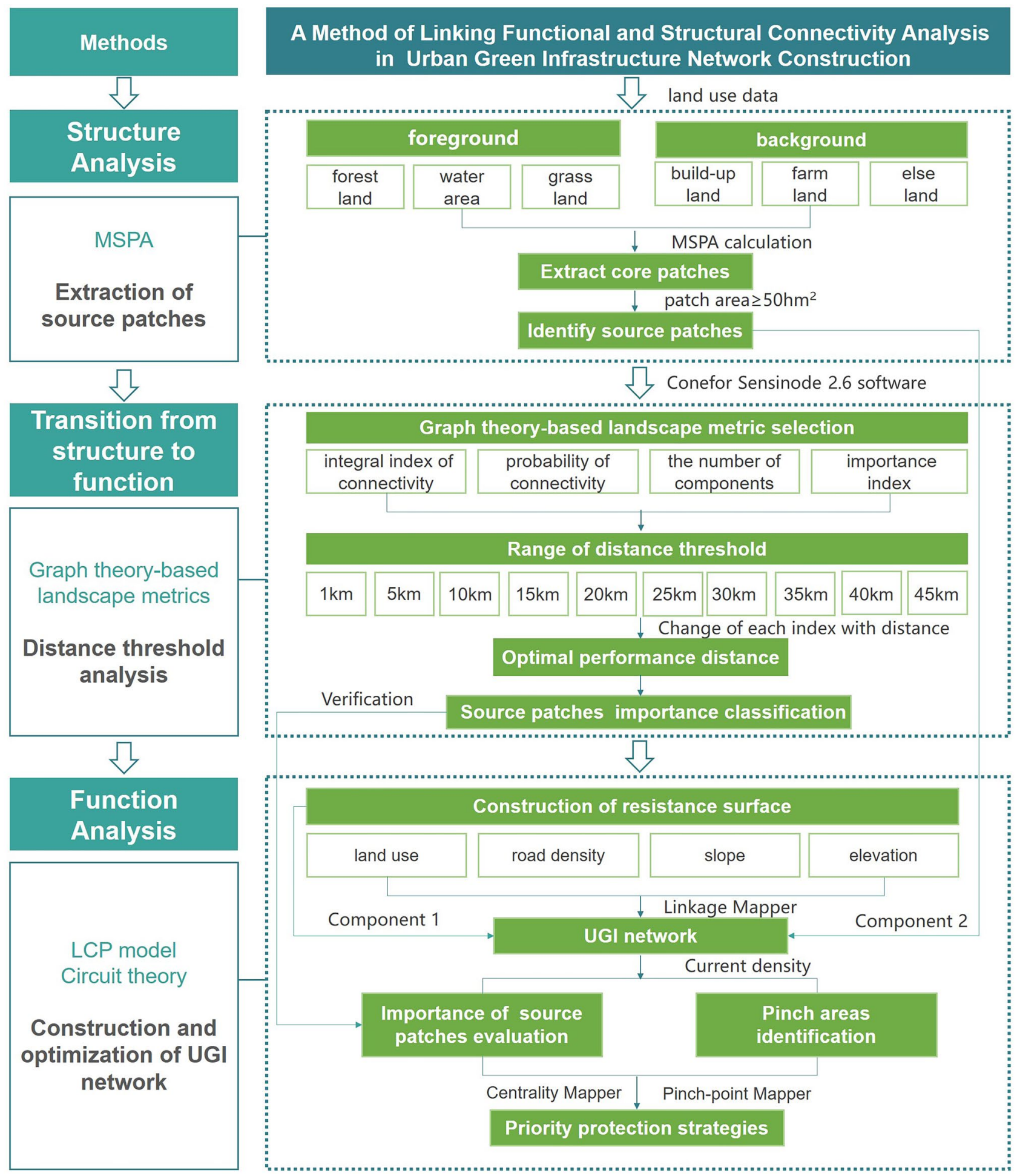

Fig. 3 Research and analysis procedures

proposed (Fig. 3). In conclusion, this framework based on MSPA, landscape connectivity metrics, and circuit theory integrates the identification of landscape elements, connectivity analysis, and network construction to realize the transition of green infrastructure network from structural connectivity to functional connectivity. 


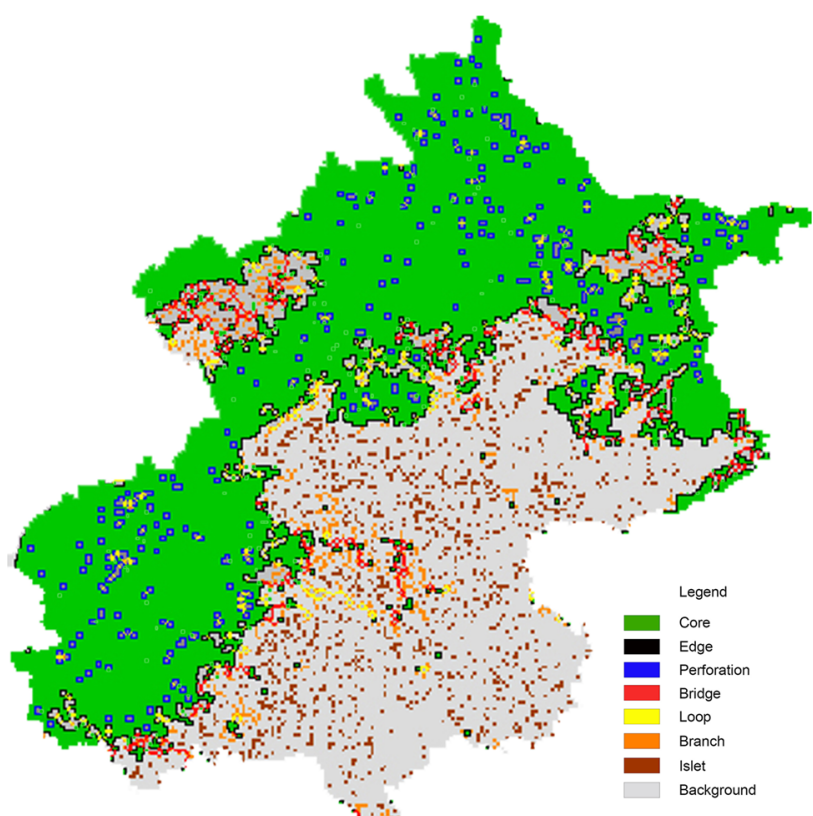

(a)

Fig. 4 Seven landscape pattern types of study area based on MSPA

\section{Results}

\section{Source patches extraction results based on MSPA landscape structure analysis}

Figure 4a shows the landscape pattern types generated by the MSPA calculations. The core patches mainly distributed in the western and northern mountain areas as well as the hilly areas. These patches provide main habitats for species and account for $44.54 \%$ of the city area. There are rich scenic resources such as natural scenic spots, national forest parks, and water source protection areas, all crucial ecological conservation areas in Beijing. The central plain area is the main urban district of Beijing, with small and scattered core patches, showing apparent two-level differentiation with the core patches in the mountain and hilly areas. The area of core patches ranges from $10 \mathrm{hm}^{2}$ to $652,039 \mathrm{hm}^{2}$, and the patch area below 50 $\mathrm{hm}^{2}$ contributed less than $1 \%$ to the regional ecological land area. Considering that patch area has a decisive impact on habitat heterogeneity and scattered small patches have little effect on regional ecosystem functions in large-scale studies, we used $50 \mathrm{hm}^{2}$ as the minimum area threshold to extract 70 core patches as source patches (Fig. 4b). Table 2 shows the

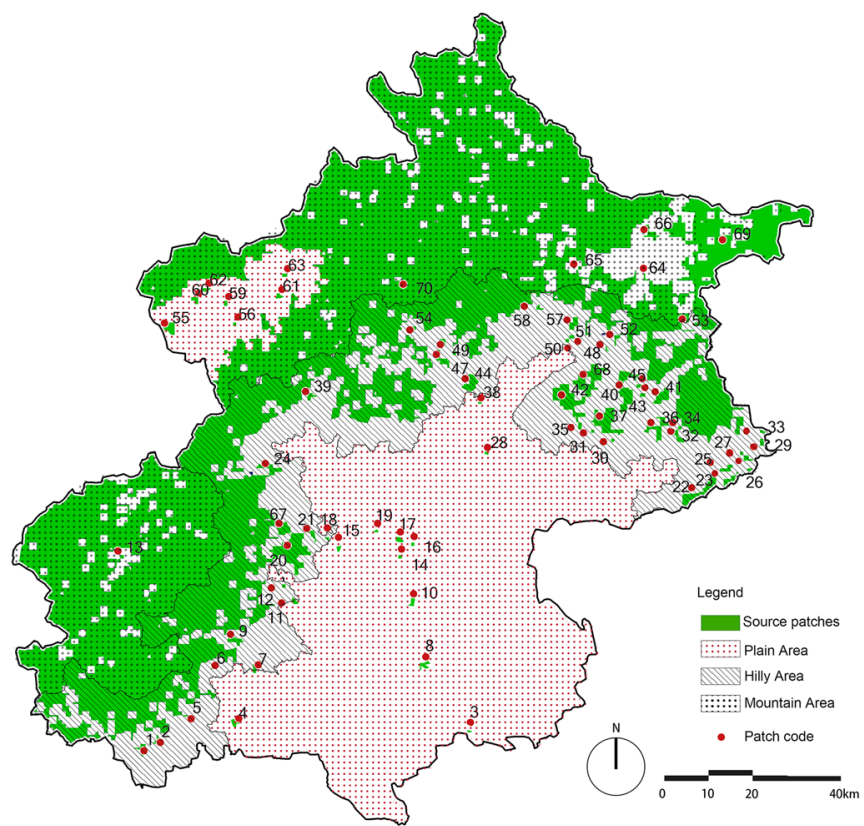

(b)

area proportions of different land use types in source patches, among which forest land is the most critical type of ecological land, with an area of $676,102.09 \mathrm{hm}^{2}$, accounting for $95.30 \%$. The remaining ecological land includes water, farmland, and grassland, accounting for $1.76 \%, 1.7 \%$, and $0.39 \%$ respectively. The total area of non-ecological land (build-up land and else land) does not exceed $1 \%$.

\section{Optimal distance threshold and importance ranking result of source patches derived from graph-theory based connection metrics}

Figure 5 shows that the NC value decreases logarithmically with the increase of dispersal distance. When the distance threshold is $1 \mathrm{~km}$, the $\mathrm{NC}$ is 70 , indicating that all patches are independent of each other and the landscape connectivity is poor. It strongly decreases from 1 to $20 \mathrm{~km}$, then drops more slowly up to $25 \mathrm{~km}$, where $\mathrm{NC}$ value generally trends to 1 and is stable further away, indicating that most of the source patches can reach a state of interconnection. Figure 6 shows that both IIC and PC values tend to increase with dispersal distance. The growth rate of IIC shows a significant turning point at $15 \mathrm{~km}$. It maintains a high growth level until

Table 2 Composition of land use types of source patches

\begin{tabular}{lccccccc}
\hline Type & forestland & water & farmland & grassland & build-up land & else & Total \\
\hline Area $\left(\mathrm{km}^{2}\right)$ & 6769.54 & 125.32 & 120.61 & 27.74 & 44.29 & 16.31 & 7103.81 \\
Proportion & $95.30 \%$ & $1.76 \%$ & $1.70 \%$ & $0.39 \%$ & $0.62 \%$ & $0.23 \%$ & $100 \%$ \\
\hline
\end{tabular}


Fig. 5 The change of NC with distance threshold

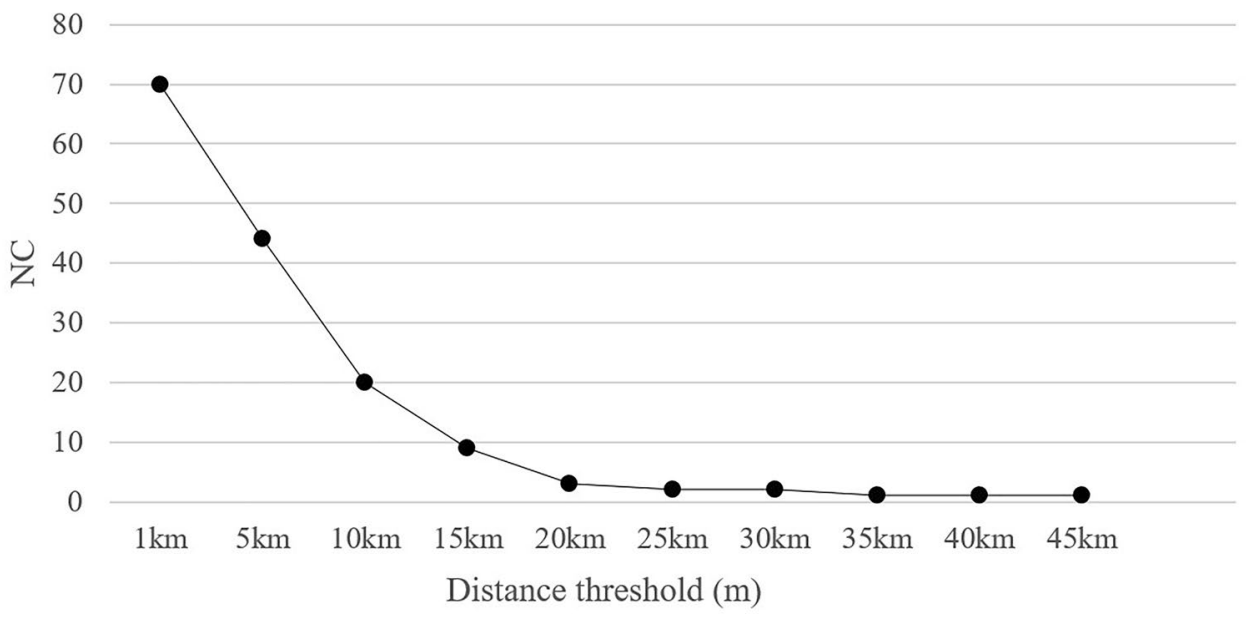

$25 \mathrm{~km}$, indicating that the landscape connectivity is significantly improved in this distance threshold. Then it increases more slowly up to $40 \mathrm{~km}$, where ICC value generally exceeds 0.89 and remains stable after that. PC value begins to show a growth trend at $5 \mathrm{~km}$, with the fastest growth rate between $20-25 \mathrm{~km}$ and then continues to grow at a slower growth rate.

Figure 7 shows the importance of individual patches of different sizes at different distances. We found that the importance of a patch is closely related to the its area whatever the distance. The most obvious is that the size of patch No. 70 is significantly larger than other patches, and its importance always occupies the dominant position. In terms of other patches, when the distance is less than $10 \mathrm{~km}$, the importance of small and medium-sized patches can not be reflected, and the proportion of patches with a dI' value greater than 0.01 is only $4 \%$. With the distance increasing to $25 \mathrm{~km}$, the importance of small and medium-sized patches increased significantly, and the proportion of patches with a
dI' value greater than 0.01 reached $75 \%$. After $25 \mathrm{~km}$, the dI' value of small and medium-sized patches fluctuates slightly, and the proportion of patches with a dI' value greater than 0.01 remain stable at around $75 \%$.

In general, IIC and PC values increase at a significant rate in the range of $15-25 \mathrm{~km}$, which means that the landscape connectivity between the source patches increases rapidly within this distance range. NC value decreases gradually after $20 \mathrm{~km}$ and finally tends to 1 , indicating that most of the source patches can reach a state of interconnection. The importance of small and medium-sized patches strongly increases from 20 to $25 \mathrm{~km}$, and the number of patches with a dI' value greater than or equal to 0.01 stabilizes at about $75 \%$ after $25 \mathrm{~km}$. Based on the above analysis results, we believe that $20-25 \mathrm{~km}$ can be used as the appropriate distance threshold for UGI network construction on the city scale. At the same time, to ensure the success rate of more species migration as far
Fig. 6 The change of ICC and $\mathrm{PC}$ with distance threshold

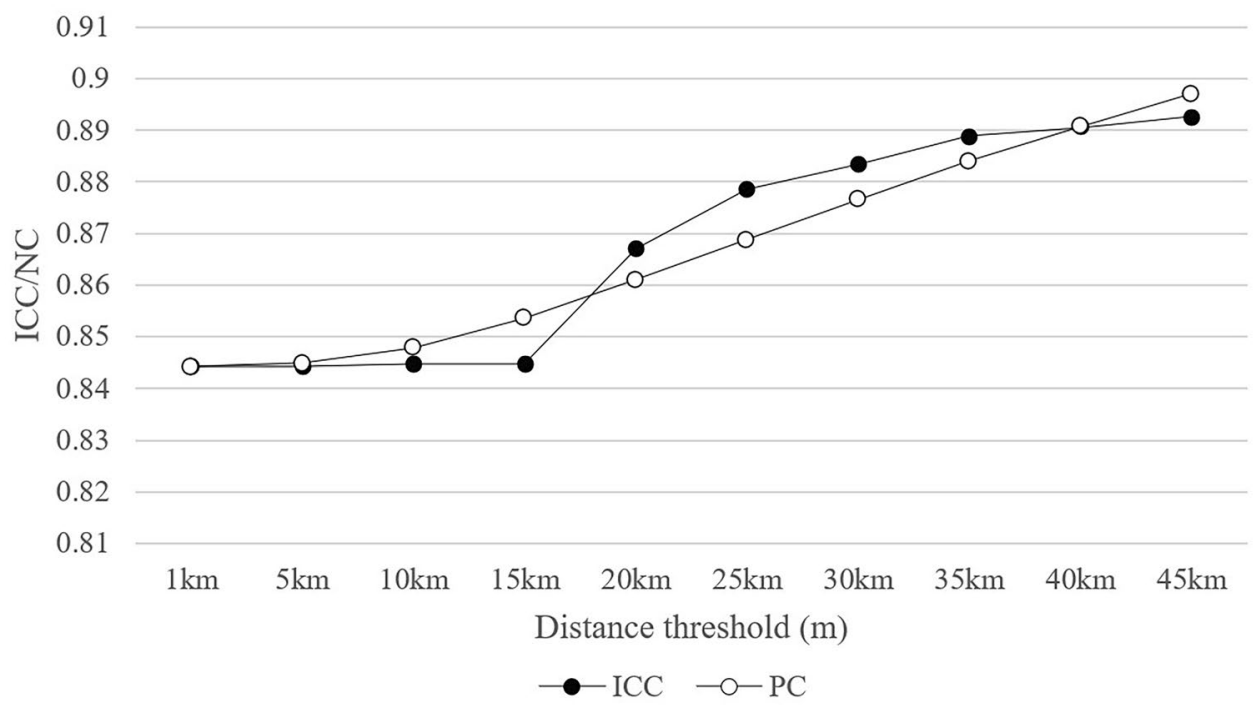




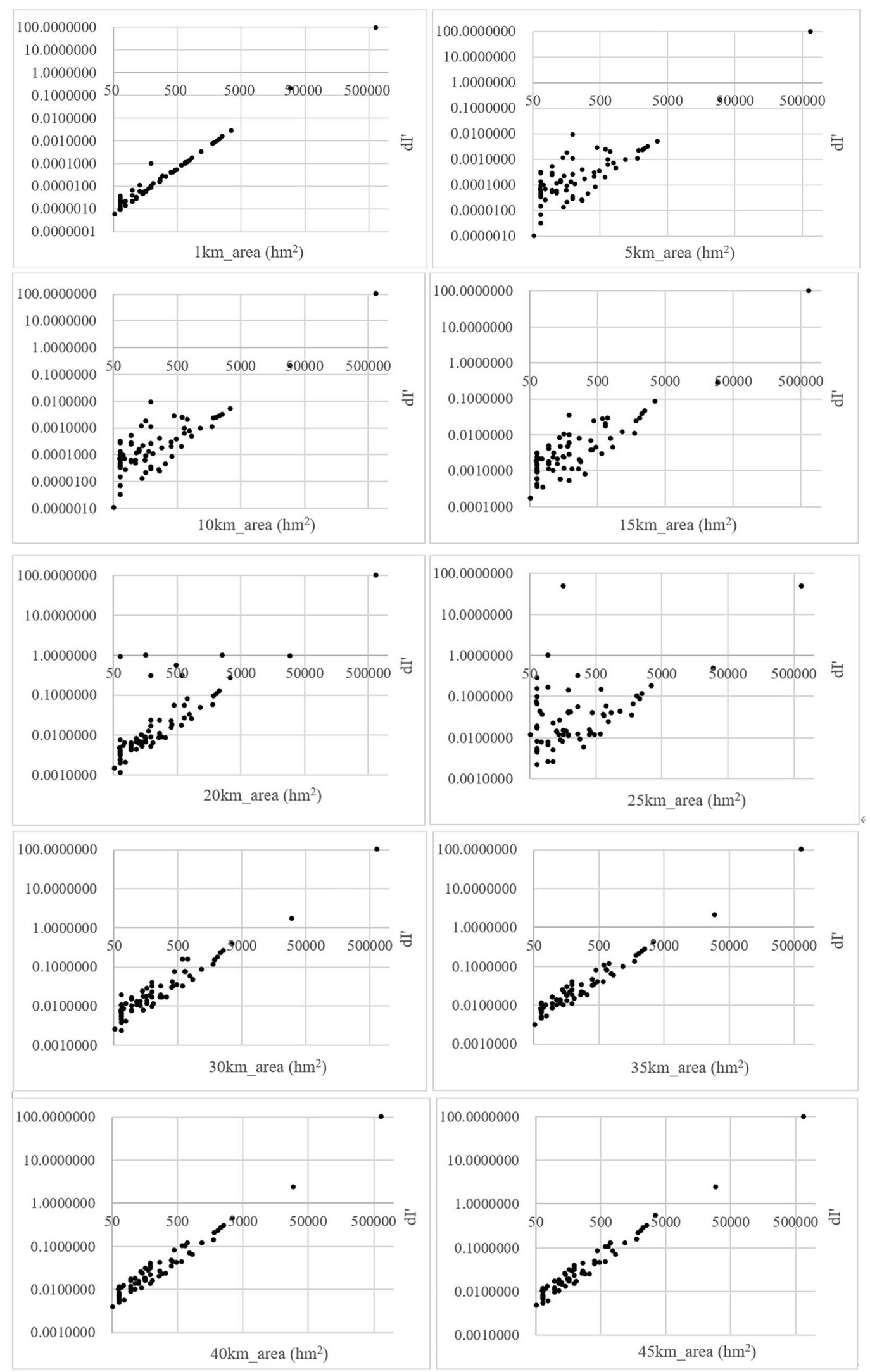

Fig. 7 The importance of individual patches of different sizes at different distances 
Fig. 8 Importance levels of source patches. Altitude of mountain area is more than $300 \mathrm{~m}$, that of hilly area is between $100-300 \mathrm{~m}$, and that of plain area is less than $100 \mathrm{~m}$

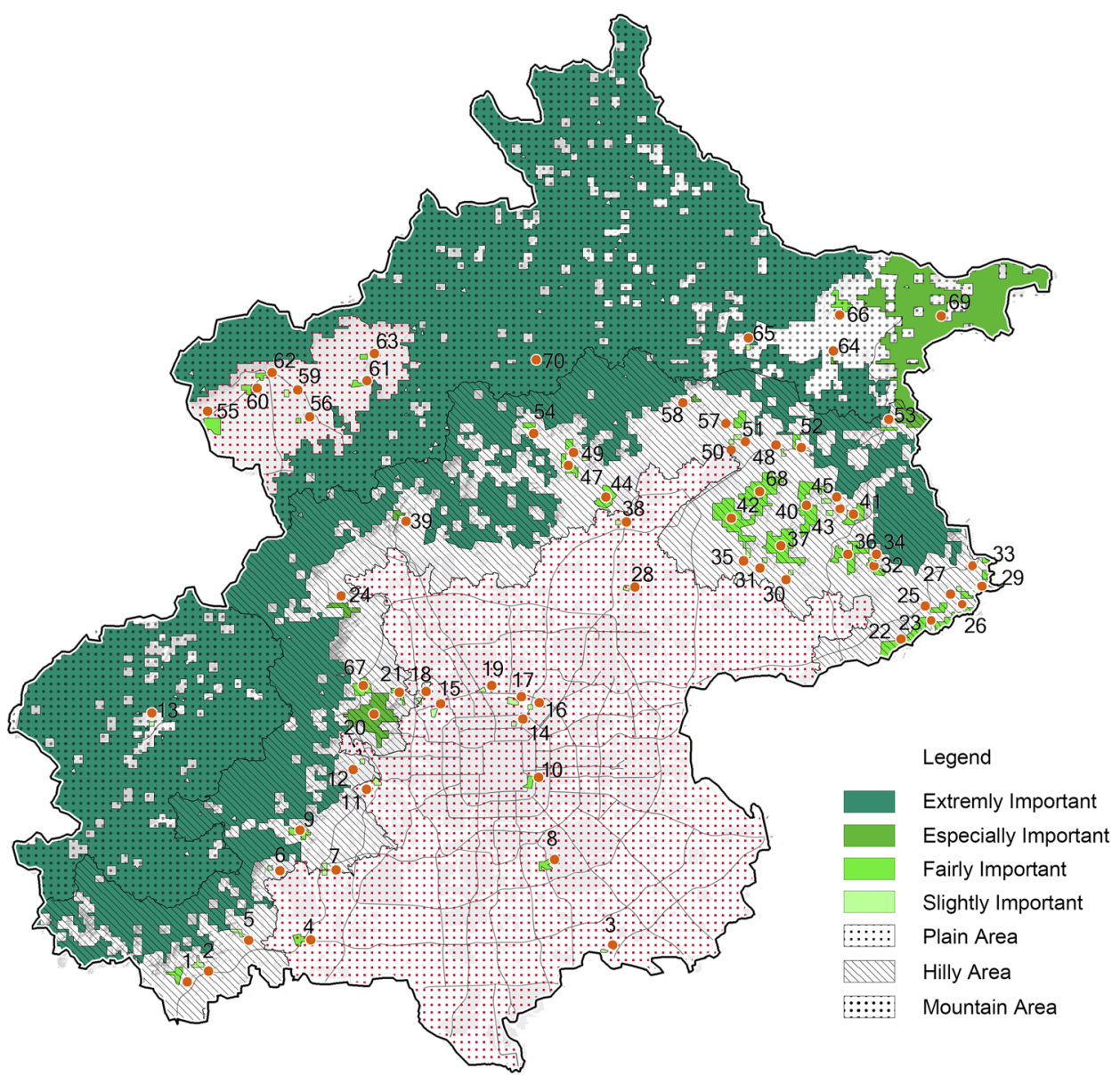

as possible to provide enough natural ecosystem services, we finally decided to take $25 \mathrm{~km}$ as the best performance distance. Figure 8 shows the importance level of source patches based on dI' values when the distance parameter was set to $25 \mathrm{~km}$. Source patches located in the western and northern mountain areas contribute the most to the overall connectivity, followed by patches located in hilly areas, and patches ian the central and eastern plain areas the least. Table 3 supplements the area and proportion of source patches with different importance levels.

\section{Construction of UGI network and identification of ecological pinch areas}

Figure 9 shows the construction result of the UGI network. Patch centrality reflects the relative contribution of each patch to the overall connectivity of the region. Centrality values of 70 source patches range from 68 to $2081 \mathrm{Amps}$, of which the most significant source patch (No.70) has the highest centrality. We found some differences between the results calculated by graph theory-based landscape metrics and those by circuit theory. For example, the results based on the dI' metric show that patch No.69 plays a vital role in improving the landscape connectivity. Still, the calculation results based on the current centrality are quite the opposite. The reason is that the graph theory-based landscape metrics give more consideration to the influence of patch shape and area on structural connectivity, while circuit theory is related to vegetation type and the number of potential corridors between patches, focusing more on the functional connectivity. Combining the two measurement methods to determine the importance of source patches is helpful to
Table 3 Total area and proportion of source patches with different importance levels

\begin{tabular}{lccccc}
\hline Type & $\begin{array}{l}\text { Extremely } \\
\text { important }\end{array}$ & $\begin{array}{c}\text { Especially } \\
\text { important }\end{array}$ & Fairly Important & Slightly important & Total \\
\hline Area $\left(\mathrm{km}^{2}\right)$ & 6520.40 & 342.91 & 88.17 & 152.33 & 7103.81 \\
Proportion & $91.79 \%$ & $4.83 \%$ & $1.24 \%$ & $2.14 \%$ & $100 \%$ \\
\hline
\end{tabular}


Fig. 9 UGI network construction result

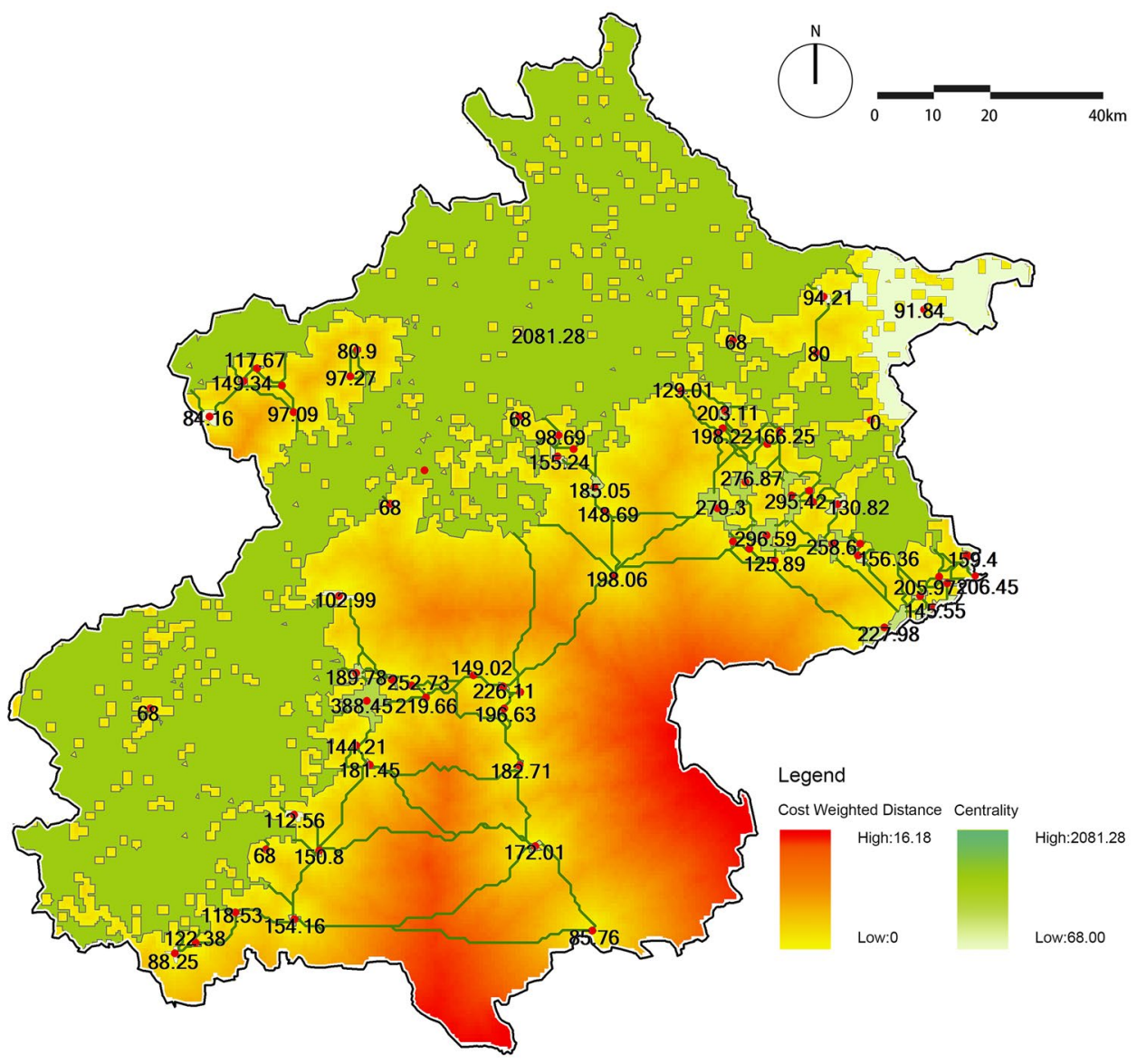

make a more scientific and comprehensive priority protection decision. We identified 148 potential corridors with a total length of $1120 \mathrm{~km}$. For the distribution, the potential corridors in mountain and hilly areas are relatively dense, but in plain areas, indeed few corridors connecting the central and western regions. Farmland and forest land constitute the primary land use types of corridors, accounting for $40.72 \%$ and $30.9 \%$ of the total corridor area, respectively (Table 4 ).

Figure 10 shows the current density of corridors and the distribution of the pinch areas within them. Most of the corridors between the source patches have high current density, indicating that these corridors are vital for species migration. Some corridors with low current density have poor connectivity. Still, there are pinch areas that are very important for maintaining connectivity where the current density is high (white rectangle frames in Fig. 9). Pinch area (a) is located in hilly areas, and its existing land types are mainly farmland and forest land, with a river passing through the area from north to south. Pinch area (b) is located at the junction of the hilly areas and the plain areas, where there are some picking gardens and villages, and the land use type is mainly farmland. Pinch area (c) is located within the water conservation area (Huairou Reservoir). Huai River is the main river in this area. It not only plays the role of flood discharge but also provides clean water for urban residents. Pinch area (d) overlaps with the existing urban river corridors, and seven urban parks have been built along the river banks as adequate protection measures to improve regional ecological quality. Pinch area (e) is located at the junction of hilly area and plain area. Wetland Park and Forest Park are critical green patches in this area, and the eastern part of the area is surrounded by urban construction land (mainly residential communities). In terms of pinch area (f), the expressway has a noticeable segmentation effect on the landscape connectivity of this area.
Table 4 Area and proportion of land use types in corridors

\begin{tabular}{lrrrrrrl}
\hline Land use type & Forestland & Grassland & Water & Farmland & Build-Up Land & Else & Total \\
\hline Area $\left(\mathrm{hm}^{2}\right)$ & $37,854.92$ & 4759.04 & 1159.37 & $46,581.67$ & $23,634.47$ & 415.31 & $114,404.77$ \\
Proportion (\%) & 33.09 & 4.16 & 1.01 & 40.72 & 20.66 & 0.36 & 100 \\
\hline
\end{tabular}


Fig. 10 Pinch areas recognition based on Circuit theory. The right satellite images show the land use around pinch areas, which are the critical positions for UGI network optimization
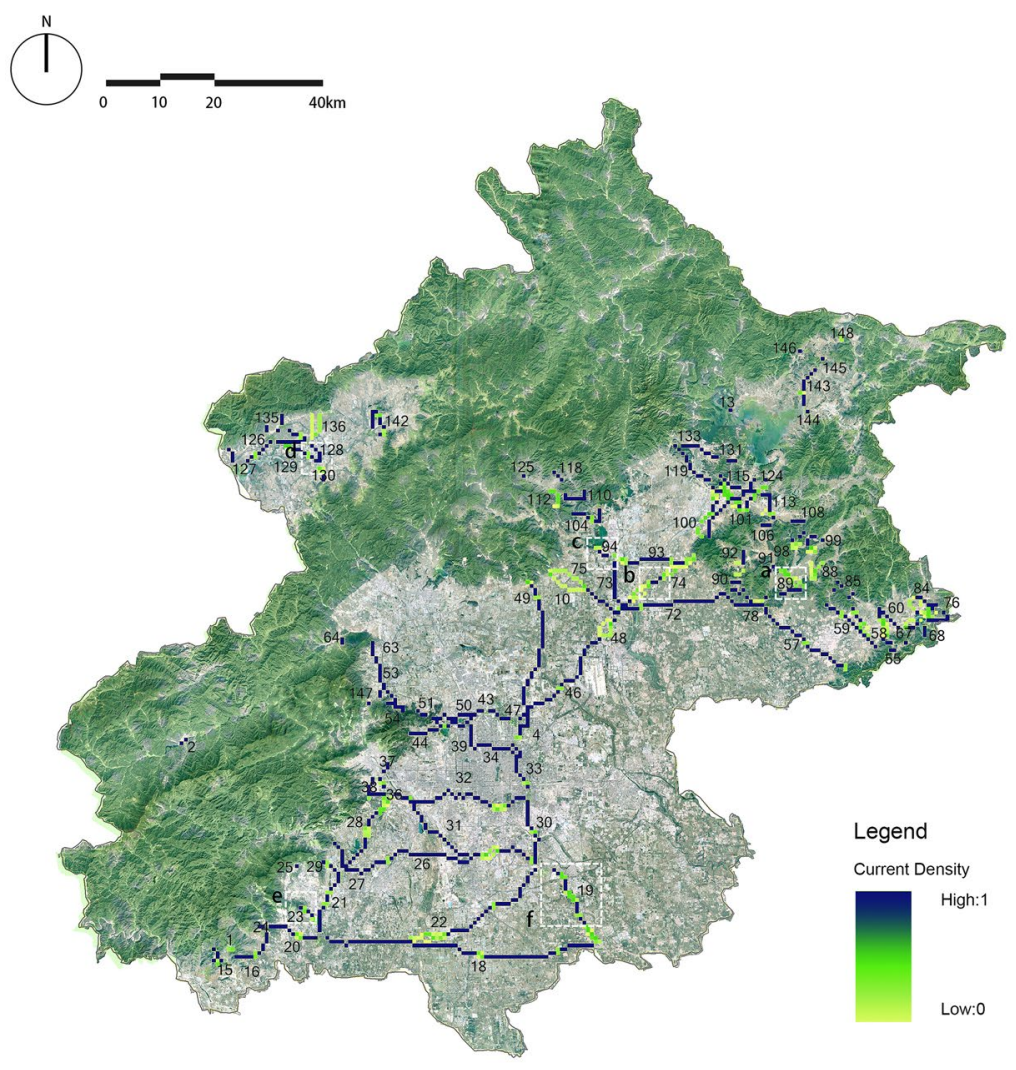

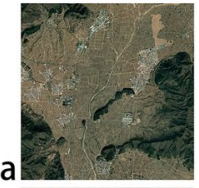

a
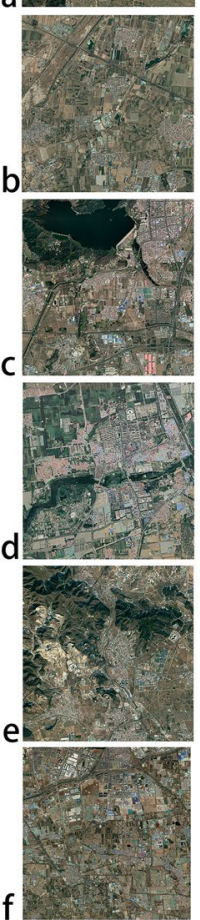

\section{Discussion}

\section{Strategies and suggestions for Beijing UGI network optimization}

The results show that $43.29 \%$ of the green space in the study area contribute significantly to landscape connectivity, covering not only the critical ecological areas such as forest parks, nature reserves, etc., but also other green space that is important for structural connection as much as possible, with a total area of $7103.81 \mathrm{~km}^{2}$. Source patches located in the western and northern mountain areas have higher forest coverage and are less affected to human intervention, which contributes the most to the overall landscape connectivity. Among them, No.70 source patch has the largest area and a wide range of radiation, which can connect the patches across the north and south of the region. It plays an irreplaceable role in ensuring regional ecological security, providing species habitats and improving landscape connectivity. Therefore, development and productive construction activities are strictly prohibited in No. 70 patch, and measures such as artificial afforestation, transformation of low-quality and low-efficiency forests should be taken to improve the quality of forest resources and cultivate forest ecosystems. Source patches in hilly areas contain rich ecosystem types such as farmland, forest, river, wetland, etc., where the ecological base is good but vulnerable to human activities. Therefore, these patches play an essential role in connecting the plain and mountain areas for species and gene diffusion. It is recommended to build a series of country parks of various types according to the characteristics of the ecosystems to form a leisure and recreational landscape belt, on the one hand to undertake and supplement part of the urban functions, on the other hand to promote the economic development of suburban villages. Source patches located in the central and eastern plains are surrounded by a large area of construction land, presenting a highly isolated spatial pattern. It is recommended to increase the number of urban micro green spaces and widen linear green spaces such as river corridors to promote biological migration in urban areas.

On this basis, we superimposed the potential corridors and the current land use and put forward the optimization strategies. The corridors between mountain and hilly areas are the key to ensure gene flow and biological migration from mountain to plain areas. They connect diverse ecosystems such as farmland, forest, and wetlands, and present the characteristics of short distance, high density, and ease of construction. The lack of these corridors will affect the material circulation and energy flow between the natural 
system inside and city's edge. The No. 100 corridor has a short length and is greatly affected by village construction activities. In addition, there are other alternative corridors in this area, so the No.100 corridor will not be included in the UGI network. No. 57 and No. 59 corridors are long and partly passing through villages. It is recommended to increase the total amount of greenery in villages with high rural construction density to reduce the resistance to species migration. For remaining corridors, cultivated land accounts for a relatively large area. It is recommended to strengthen the protection of current natural resources and build forest parks or wetland parks to increase various types of ecological land. In plain areas, due to the impact of urban roads and construction land on biological migration, the identified potential corridors are characterized by long distance, small quantity, and high construction difficulty. No. 32 corridor is not recommended to be included in the UGI network due to the long distance and the relatively small area of green space inside the corridor. The length of No.18, No.22, No.26, No.46, and No.49 corridor is more than $2.5 \mathrm{~km}$. It is suggested to increase urban parks and street green spaces based on the existing greenway system and river corridors as stepping stones for wildlife migration. At the intersection of roads with high traffic volume and potential corridors, wildlife bridges and green avenues should be built to improve the success rate of wildlife migration.

Finally, according to the environmental characteristics around the different pinch areas, corresponding optimization suggestions are put forward. For pinch area (a), it is suggested that the farmland within $15 \mathrm{~m}$ on both sides of the river should be converted into green space as a buffer zone, or wetland parks should be built in the upstream area to protect the habitat quality effectively. Pinch area (b) is highly vulnerable to urban construction and expansion, so the construction intensity and development mode near corridors must be strictly enforced in future development plans. For pinch area (c), the ecological land along the Huai River now is surrounded by construction land or cut by roads, so it is urgent to build a vegetation buffer zone with a suitable width and to create a habitat conducive to the growth of aquatic plants, the foraging and breeding of benthos and fish in combination with the restoration of riverbed sediment diversity. For pinch area (d), a continuous riverside park system can be constructed based on the existing good habitat quality. Pinch area (e) is located at the junction of hilly area and plain area, which directly affects the successful migration of species. It is necessary to appropriately supplement community green spaces, pocket parks, and other small "stepping stones" to reduce barrier effects of build-up land. For pinch area (f), it is recommended to connect the fragmental green patches by strengthening the construction of a protective greenbelt to maximize the connectivity between the source patches.

\section{Advantages of combining MSPA, connectivity metrics and circuit theory to establish UGI network}

We discussed how to integrate MSPA, connectivity metrics and circuit theory to construct UGI and ascertain the importance of its elements that meets the needs of landscape structure connectivity and functional connectivity in UGI construction, and provides a new research perspective for UGI construction and optimization. This method avoids the subjectivity of identifying the source patches and corridors, especially the circuit theory which combines the characteristics of electronic random walk and is different from previous landscape connectivity models. It shows obvious advantages in simulating the movement and diffusion process of species. The feasibility and usability of this method in UGI planning applications were verified by comparing the pinch identification results with satellite images.

One key feature of MSPA is that it can automatically and objectively identify core patches and other landscape pattern classes (Ostapowicz et al. 2008), and this feature can not be achieved with other methodologies like Fragstats landscape indices ( $\mathrm{Li}$ and $\mathrm{Wu} 2004$ ) or graph theoretic approaches (Urban and Keitt 2001, Fall et al. 2007). Landscape connectivity metric provides a good compromise to bridge the goals of adequate correlation between functional and structural connectivity, which is supposed to be a tool for landscape planning decision support. It not only quantifies the importance of source patch, but also explores the distance threshold that is conducive to enhancing connectivity (Saura and Torné 2009). Circuit theory combines the characteristics of the electronic random walk and shows a great advantage in simulating species diffusion in the absence of experimental data based on field investigation of species diffusion behavior. It can also determine the relative importance of source patches and identify the pinch areas in the network. This is a key step that other connectivity models (e.g., LCP and MSPA) are difficult to achieve, which is of great significance for making UGI network priority protection strategies.

\section{Challenges and limitations in the process of UGI network construction}

A reasonable setting of landscape resistance value is one of the challenges of the effective application of the model. To lower the subjectivity in landscape resistance evaluation, we combined 4 resistance evaluation layers with the research purpose (MSPA landscape pattern, land use type, slope and elevation), but in fact, strong subjectivity still remained. When assigning the value of each resistance layer according to empirical values or theoretical methods, the influence of patch heterogeneity and species diffusion behavior on the resistance value is ignored. In future research, we need to consider the migration and diffusion 
characteristics of different species, and make reasonable valuations based on observational and experimental research. In addition, this works is generalized in respect to species. How can this be expanded to become multilayered for multiple indigenous species is also a necessary question to be discussed in the future research. Perhaps a more detailed classification of migration distances or habitat needs of different multiple indigenous species can better explain this problem. Finally, it should be noted that due to the strong randomness of species migration, ideally, in order to achieve more realistic analysis results, the input and analysis boundaries should be larger. In this study, we took the regionalization map of Beijing district as the research scope, which brought inevitable errors when we evaluated the patches near the boundary. In the further study, we may consider the establishment of buffer zone to reduce the error caused by the administrative boundary.

\section{Conclusion}

Urbanization and human activities have a serious impact on the connectivity of green space. Optimizing UGI is an effective method to improve the connectivity of ecological space, protect biodiversity and promote the orderly expansion of cities. Took Beijing as the study area, firstly, we extracted source patches and explored the optimal distance threshold that is conducive to the improvement of connectivity based on MSPA and landscape connectivity metrics. Then, potential connecting corridors which have important contributions to regional landscape connectivity were identified by circuit theory. According to the current density, the relative importance of source patches was analysed, and the pinch areas affecting corridor connectivity were identified for network optimization. The results showed that the distance threshold of $20-25 \mathrm{~km}$ is most conducive to improving the landscape connectivity of the region. Large source patches in mountain and hilly areas of Beijing are important to guarantee the supply of urban natural ecosystem services. The number of source patches in central plain areas was small and scattered due to urban construction encroachment, which can barely maintain ecological connectivity with patches in mountain and hilly areas. Therefore, we suggested that the protective actions such as returning farmland to forest should be implemented in pinch areas for species migration, and the ties between different regions should be strengthened.

In this study, the evaluation of structural and functional connectivity was regarded as the basis of UGI network construction. Circuit theory can identify all potential corridors and analyse their relative importance, which provides a simple and feasible method framework for the construction and optimization of urban UGI networks. However, circuittheoretic models abstract and simplify the process of species movement between different landscape units, and some parameters are set based on relevant theoretical assumptions. We should further study the characteristics of species migration and obtain experimental data to modify the model, and promote the application of circuit theory in the field of landscape planning. The research results can provide a scientific basis for the protection planning of the fragmented UGI network and the design of connecting corridors, and have important theoretical guiding significance for the construction of other ecological networks.

Supplementary information The online version contains supplementary material available at https://doi.org/10.1007/s11252-022-01201-2.

Acknowledgements The authors express their gratitude to Dr. Li Fangzheng who provided expert advice on green infrastructure construction method during the early planning stages of this research and to WangXin and Niyongwei, who conducted the land use type surveys. The authors also would like to express their gratitude to EditSprings (https://www.editsprings.com/) for the expert linguistic services provided.

Author contributions Conceptualization, L.Y. and Z.X.; methodology, L,Y, and H.T.T.; validation, L.Y.; formal analysis, L.Y. and H.T.T; investigation, L.Y.; resources, L.Y; data curation, L.Y.; writingoriginal draft preparation, L.Y.; writing-review and editing, L.Y. and H.T.T.; visualization, L.Y.; supervision, L.Y. and Z.X.; project administration, Z.X.; funding acquisition, Z.X. All authors have read and agreed to the published version of the manuscript.

Funding Supported by the National Key Research and Development Program of China (No. 2019YFD11004021): Construction of rural landscape evaluation system.

Data availability The Land-Sat 8 remote sensing satellite data and digital elevation data with a spatial resolution of $30 \mathrm{~m}$ were downloaded from Geospatial Data Cloud (http://www.gscloud.CN). Atlas of the Beijing Overall Planning (2016-2035) were downloaded from Beijing Municipal Commission of Planning and Natural Resources (http:// ghzrzyw.beijing.gov.cn/). Other data in the analysis process can be requested via the author Liu Yang: 863,833,260@qq.com.

\section{Declarations}

Competing interests The authors declare that they have no conflict of interest.

Open Access This article is licensed under a Creative Commons Attribution 4.0 International License, which permits use, sharing, adaptation, distribution and reproduction in any medium or format, as long as you give appropriate credit to the original author(s) and the source, provide a link to the Creative Commons licence, and indicate if changes were made. The images or other third party material in this article are included in the article's Creative Commons licence, unless indicated otherwise in a credit line to the material. If material is not included in the article's Creative Commons licence and your intended use is not permitted by statutory regulation or exceeds the permitted use, you will 
need to obtain permission directly from the copyright holder. To view a copy of this licence, visit http://creativecommons.org/licenses/by/4.0/.

\section{References}

Alberti M, Marzluff JM (2004) Ecological resilience in urban ecosystems: Linking urban patterns to human and ecological functions. Urban Ecosyst 7:241-265. https://doi.org/10.1023/B:UECO. 0000044038.90173.c6

An Y, Liu S, Sun Y, Shi FN, Beazley R (2020) Construction and optimization of an ecological network based on morphological spatial pattern analysis and circuit theory. Landsc Ecol. https://doi.org/ 10.1007/s10980-020-01027-3

Banks-Leite C, Ewers RM, Metzger JP (2010) Edge effects as the principal cause of area effects on birds in fragmented secondary forest. Oikos 119:918-926. https://doi.org/10.1111/j.1600-0706. 2009.18061.x

Battisti C (2013) Ecological network planning from paradigms to design and back: a cautionary note. J Land Use Sci 8:215-223. https://doi.org/10.1080/1747423X.2011.639098

Beier P, Majka DR, Newell SL (2009) Uncertainty analysis of leastcost modeling for designing wildlife linkages. Ecol Appl 19:20672077. https://doi.org/10.1890/08-1898.1

Breuste J, Artmann M, Li J, Xie M (2015) Special issue on green infrastructure for urban sustainability. J Urban Plann Dev 141:A2015001-A2015005. https://doi.org/10.1061/(ASCE)UP. 1943-5444.0000291

Bueno JA, Tsihrintzis VA, Alvarez L (1995) South Florida greenways: a conceptual framework for the ecological reconnectivity of the region. Landsc Urban Plan 33:247-266. https://doi.org/10.1016/ 0169-2046(94)02021-7

Calabrese JM, Fagan WF (2004) A comparison-shopper's guide to connectivity metrics. Front Ecol Environ 2:529-536. https://doi.org/ 10.1890/15409295\%282004\%29002\%5B0529\%3AACGTCM\% 5D2.0.CO\%3B2

Capotorti G, Mollo B, Zavattero L, Anzellotti I, Celesti-Grapow L (2015) Setting priorities for urban forest planning. a comprehensive response to ecological and social needs for the metropolitan area of Rome (Italy). Sustainability 7:3958-3976. https://doi.org/ $10.3390 /$ su 7043958

Carlier J, Moran J (2019) Landscape typology and ecological connectivity assessment to inform greenway design. Sci Total Environ 651:3241-3252. https://doi.org/10.1016/j.scitotenv.2018.10.077

Carlson C, Canty D, Steiner F et al (1989) A path for the Palouse: An example of conservation and recreation planning. Landsc Urban Plan 17:1-19

Carroll C, Mcrae BH, Brookes A (2012) Use of linkage mapping and centrality analysis across habitat gradients to conserve connectivity of gray wolf populations in western north America. Conserv Biol 26:78-87. https://doi.org/10.1111/j.1523-1739.2011.01753.x

Cimon-Morin J, Poulin M (2018) Setting conservation priorities in cities: approaches, targets and planning units adapted to wetland biodiversity and ecosystem services. Landsc Ecol 33:1975-1995. https://doi.org/10.1007/s10980-018-0707-z

Correa Ayram CA, Mendoza ME, Etter A, Salicrup DRP (2016) Habitat connectivity in biodiversity conservation: A review of recent studies and applications. Prog Phys Geogr 40:7-37. https://www. researchgate.net/publication/281408475

Cushman SA, Landguth EL, Flather CH (2013) Evaluating population connectivity for species of conservation concern in the American great plains. Biodivers Conserv 22:2583-2605. https://doi.org/10. 1007/s10531-013-0541-1

Dickson BG, Albano CM, Anantharaman R, Beier P, Fargione J, Graves TA, Gray ME, Hall KR, Lawler JJ, Leonard PB, Littlefield
CE, McClure ML, Novembre J, Schloss CA, Schumaker NH, Shah VB, Theobald DM (2019) Circuit-theory applications to connectivity science and conservation. Conserv Biol 33:239-249. https:// doi.org/10.1111/cobi.13230

Dige G (2011) Green infrastructure and territorial cohesion. The concept of green infrastructure and its integration into policies using monitoring systems. EAA Technical report. retrived January 10, 2020. from http://www.eea.europa.eu/publications/green-infra structure-and-territorial-cohesion

Fall A, Fortin MJ, Manseau M, O'Brien D (2007) Spatial graphs: principles and applications for habitat connectivity. Ecosystems 10:448-461. https://doi.org/10.1007/s10021-007-9038-7

Fenu G, Pau P (2018) Connectivity analysis of ecological landscape networks by cut node ranking. Appl Netw Sci 3:22. https://doi. org/10.1007/s41109-018-0085-0

Ferrari B, Quatrini V, Barbati A, Corona P, Masini E, Russo D (2019) Conservation and enhancement of the green infrastructure as a nature-based solution for Rome's sustainable development. Urban Ecosystems 22:865-878. https://doi.org/10.1007/ s11252-019-00868-4

Grafius DR, Corstanje R, Siriwardena GM, Plummer KE, Harris JA (2017) A birds eye view: using circuit theory to study urban landscape connectivity for birds. Landsc Ecol 32:1771-1787. https:// doi.org/10.1007/s 10980-017-0548-1

Harris LD, Scheck J (1991) From implications to applications: the dispersal corridor principle applied to the conservation of biological diversity. Nature conservation 2: the role of corridors. 189-220. retrived June 6, 2020. from https://www.researchgate.net/publication/279598253_ From_implications_to_applications_the_dispersal_corridor_principle_ applied_to_the_conservation_of_biological_diversity

Huang H, Yu KY, Gao YL, Liu J (2019) Building green infrastructure network of Fuzhou using MSPA. Chin Landsc Archit 35: 70-75. retrived July 15, 2020. from https://kns.cnki.net/kcms/ detail/detail.aspx ?dbcode $=$ CJFD $\&$ dbname $=$ CJFDLAST2020 $\&$ filename $=$ ZGYL201911013\&v $=$ TT1 $\mathrm{cm} 8$ VLX $\% 25 \mathrm{mmd} 2 \mathrm{BrlyS} \%$ 25mmd2B32phrREkGVK9g1S3no\%25mmd2FSjQX\%25mmd 2FNLdyYDZFIYHvE3NJ64D99DUaE

Kavanagh P, Newlands N, Christensen V, Pauly D (2004) Automated parameter optimization for ecopath ecosystem models. Ecol Model 172:141-149. https://doi.org/10.1016/j.ecolmodel.2003.09.004

$\mathrm{Li} \mathrm{H}, \mathrm{Wu} \mathrm{J}$ (2004) Use and misuse of landscape indices. Landsc Ecol 19:389-399. https://doi.org/10.1023/B:LAND.0000030441.15628.d6

Liu CF, Zhou B, He XY, Chen W (2010) Selection of distance thresholds of urban forest landscape connectivity in Shenyang City. Chin J Appl Ecol 21: 2508-2516. http://www.cjae.net/CN/Y2010/V21/I10/2508

Lookingbill TR, Minor ES (2017) Assessing Multi-Scale Landscape Connectivity Using Network Analysis. In: Gergel S, Turner M (eds) Learning Landscape Ecology. Springer, New York, NY. https://doi.org/10.1007/978-1-4939-6374-4_12

Mace GM, Ken N, Fitter AH (2012) Biodiversity and ecosystem services: a multilayered relationship. Trends Ecol Evol 27:19-26. https://doi.org/10.1016/j.tree.2011.08.006

Madureira H, Andresen T, Monteiro A (2011) Green structure and planning evolution in porto. Urban for Urban Green 10:141-149. https://doi.org/10.1016/j.ufug.2010.12.004

McRae BH, Beier P (2007) Circuit theory predicts gene flow in plant and animal populations. Proc Natl Acad Sci 104:19885-19890 https://www.pnas.org/content/104/50/19885

McRae BH, Dickson BG, Keitt TH, Shah VB (2008) Using circuit theory to model connectivity in ecology, evolution, and conservation. Ecology 89:2712-2724. https://doi.org/10.1890/07-1861.1

McRae BH, Shah VB, Edelman A (2016) Circuitscape: modeling landscape connectivity to promote conservation and human health. The Nature Conservancy 14. retrived January 10, 2020. from https:// www.researchgate.net/publication/304835052_Circuitscape_ 
modeling_landscape_connectivity_to_promote_conservation_ and_human_health

Ostapowicz K, Vogt P, Riitters KH, Kozak J, Estreguil C (2008) Impact of scale on morphological spatial pattern of forest. Landsc Ecol 23:1107-1117. https://doi.org/10.1007/s10980-008-9271-2

Pascual-Hortal L, Saura S (2006) Comparison and development of new graph-based landscape connectivity indices: towards the priorization of habitat patches and corridors for conservation. Landsc Ecol 21:959-967. https://doi.org/10.1007/s10980-006-0013-z

Qi K, Fan ZQ (2016) Evaluation method for landscape connectivity based on graph theory: a case study of natural forests in Minqing County, Fujian Province. Acta Ecol Sin 36:7580-7593. https:// doi.org/10.5846/stxb201507301599

Quatrini V, Tomao A, Corona P, Ferrari B, Masini E, Agrimi M (2019) Is new always better than old? accessibility and usability of the urban green areas of the municipality of Rome. Urban for Urban Green 37:126-134. https://doi.org/10.1016/j.ufug.2018.07.015

Rayfield B, Fortin MJ, Fall A (2011) Connectivity for conservation: a framework to classify network measures. Ecology 92:847-858. https://doi.org/10.1890/09-2190.1

Riitters K, Vogt P, Soille P, Estreguil C (2009) Landscape patterns from mathematical morphology on maps with contagion. Landsc Ecol 24:699-709. https://doi.org/10.1007/s10980-009-9344-x

Saura S, Pascual-Hortal L (2007) A new habitat availability index to integrate connectivity in landscape conservation planning: Comparison with existing indices and application to a case study. Landsc Urban Plan 83:91-103. https://doi.org/10.1016/j.landurbplan.2007.03.005

Saura S, Torné J (2009) A software package for quantifying the importance of habitat patches for landscape connectivity. Environ Model Softw 24: 135-139. https://doi.org/10.1016/j.envsoft.2008.05.005

Shi XM, Qin MZ (2018) Research on the optimization of regional green infrastructure network. Sustainability 10:46-49. retrived May 6, 2020. from https://www.mdpi.com/2071-1050/10/12/4649

Shukla A, Jain K (2019) Critical analysis of spatial-temporal morphological characteristic of urban landscape. Arab J Geosci 12:112. https://doi.org/10.1007/s12517-019-4270-y

Soille P, Vogt P (2009) Morphological segmentation of binary patterns. Pattern Recogn Lett 30:456-459. https://doi.org/10.1016/j. patrec.2008.10.015

Song LL, Qin MZ (2016) Identification of ecological corridors and its importance by integrating circuit theory. J Appl Ecol 27:33443352. https://doi.org/10.13287/j.1001-9332.201610.035

Spear SF, Balkenhol N, Fortin MJ, Mcrae BH, Scribner K (2010) Use of resistance surfaces for landscape genetic studies: considerations for parameterization and analysis. Mol Ecol 19:3576-3591. https://doi.org/10.1111/j.1365-294X.2010.04657.x

Uezu A, Metzger JP, Vielliard JM (2005) Effects of structural and functional connectivity and patch size on the abundance of seven atlantic forest bird species. Biol Conserv 123: 507-519. https:// doi.org/10.1016/j.biocon.2005.01.001

Urban D, Keitt T (2001) Landscape connectivity: a graph-theoretic perspective. Ecology 82:1205-1218. https://doi.org/10.1890/ 0012-9658(2001)082[1205:LCAGTP]2.0.CO;2

van Schalkwyk J, Pryke JS, Samways MJ, Gaigher R (2020) Corridor width determines strength of edge influence on arthropods in conservation corridors. Landsc Ecol 35:1175-1185. https://doi.org/ 10.1007/s10980-020-01008-6

Verbeylen G, De Bruyn L, Adriaensen F, Matthysen E (2003) Does matrix resistance influence Red squirrel (Sciurus vulgaris L. 1758) distribution in an urban landscape? Landsc Ecol 18:791805. https://doi.org/10.1023/B:LAND.0000014492.50765.05

Verdú-Vázquez A, Fernández-Pablos E, Lozano-Diez RV, López-Zaldívar O (2021) Green space networks as natural infrastructures in PERIURBAN areas. Urban Ecosyst 24:187-204. https://doi.org/10.1007/ s11252-020-01019-w

Vogt P, Ferrari JR, Lookingbill TR, Gardner RH, Riitters KH, Ostapowicz K (2009) Mapping functional connectivity. Ecol Ind 9:64-71. https:// doi.org/10.1016/j.ecolind.2008.01.011

Wang BY, Liu ZC (2019) Functional connectivity analyses and construction strategies of the structure of green space network in Haidian district of Beijing. Landsc Archit Front 7:34-51. https:// doi.org/10.15302/J-LAF-20190104

Wickham JD, Riitters KH, Wade TG, Vogt P (2009) A national assessment of green infrastructure and change for the conterminous united states using morphological image processing. Landsc Urban Plan 94:186-195. https://doi.org/10.1016/j.landurbplan.2009.10.003

Xu F, Yin HW, Kong FH, Xu JG (2015) Developing ecological networks based on MSPA and the least-cost path method: A case study in bazhong western new district. Acta Ecol Sin 35:64256434. https://doi.org/10.5846/stxb201402130248

Ye JS (2019) Chapter two: Overwintering spatial behavior of Anatidae. In: Overwintering spatial behavior and habitat utilization characteristics of Anatidae in the East End of Pudong District, Shanghai. East China Normal University, Shanghai

Yin Y, Liu S, Sun Y, Zhao S, An Y, Dong S, Coxixo A (2019) Identifying multispecies dispersal corridor priorities based on circuit theory: A case study in Xishuangbanna, Southwest China. J Geogr Sci 29:1228-1245. https://doi.org/10.1007/s11442-019-1655-5 